\title{
Faktor Risiko yang Berhubungan dengan Kejadian Kelainan Bawaan pada Neonatus
}

\author{
Febriano Matthew, ${ }^{1}$ Rocky Wilar, ${ }^{2}$ Adrian Umboh $^{2}$
}

\author{
${ }^{1}$ Program Studi Pendidikan Dokter Fakultas Kedokteran Universitas Sam Ratulangi, Manado, \\ Sulawesi Utara, Indonesia \\ ${ }^{2}$ Bagian Ilmu Kesehatan Anak Fakultas Kedokteran Universitas Sam Ratulangi/RSUP Prof. \\ Dr. R. D. Kandou, Manado, Sulawesi Utara, Indonesia \\ Email: 17011101101@student.unsrat.ac.id
}

\begin{abstract}
Congenital abnormalities are one of the main causes of infant mortality worldwide. Their symptoms vary from mild to severe. This study was aimed to determine the risk factors associated with the incidence of congenital abnormalities. This was a literature review study. The results obtained 10 articles that discussed about the risk factors of congenital abnormalities. The incidence of congenital abnormalities was more common in males. The most common factor was the maternal age of 20+ years Especially in Indonesia, there was no significant data about the risk factors related to the incidence of congenital abnormalities, however, two journals from Indonesia showed an increased incidence of congenital abnormalities in women infected during pregnancy. In addition, there were other risk factors found only in one to two journals, such as exposure to cigarettes, consumption of drugs or narcotics, and family history of previous congenital disorders. The review also covered several congenital disorders classified in organ systems dominated by the cardiovascular system. In conclusion, the risk factors associated with congenital abnormalities are maternal age, multiparity, history of abortion, congenital abnormalities in previous pregnancies, gestational diabetes, exposure to cigarette smoke, consumption of alcohol, consumption of drugs, not taking folic acid, family history of congenital abnormalities, consanguinity, and low socioeconomic status
\end{abstract}

Keywords: risk factor, birth defect, congenital anomalies, neonates

\begin{abstract}
Abstrak Kelainan kongenital merupakan salah satu penyebab utama kematian bayi di dunia dengan gejala bervariasi dari ringan hingga berat. Penelitian ini bertujuan untuk mengetahui faktor risiko yang berhubungan dengan kejadian kelainan kongenital. Jenis penelitian ialah literature review. Hasil penelitian mendapatkan 10 artikel mengenai faktor risiko kejadian kelainan kongenital. Kejadian kelainan kongenital lebih sering terjadi pada jenis kelamin laki-laki. Faktor risiko yang paling sering ialah usia ibu saat hamil mulai 20 tahun hingga lebih. Khusus di Indonesia belum ada data bermakna yang menunjukkan faktor risiko yang berhubungan dengan kejadian kelainan kongenital, namun dua artikel dari Indonesia menunjukkan peningkatan kejadian kelainan kongenital pada ibu yang terinfeksi saat hamil. Faktor risiko lainnya yang hanya didapatkan pada satu hingga dua jurnal saja seperti, paparan rokok, konsumsi obat maupun narkoba, serta riwayat keluarga yang pernah mengalami kejadian kelainan bawaan sebelumnya. Hasil kajian juga mendapatkan beberapa diagnosis penyakit kelaianan kongenital yang di golongkan dalam sistem organ, didominasi oleh sistem kardiovaskular. Simpulan penelitian ini ialah faktor risiko yang berhubungan dengan kelainan kongenital ialah usia ibu, multiparitas, riwayat abortus, kelainan ba kongenital waan pada kehamilan sebelumnya, diabetes gestasional, paparan asap rokok, konsumsi alkohol, konsumsi obat-obatan, tidak mengonsumsi asam folat, riwayat keluarga mengalami kelainan kongenital, adanya hubungan darah antara ayah dan ibu, dan status sosioekonomi rendah
\end{abstract}

Kata kunci: faktor resiko, kelainan kongenital, neonatus 


\section{PENDAHULUAN}

Kelainan kongenital atau biasa disebut juga kelainan bawaan didefinisikan sebagai anomali struktural atau fungsional yang terjadi selama kehidupan intrauterin dan dapat diidentifikasi sebelum lahir, saat lahir, atau terkadang hanya dapat dideteksi di kemudian hari. ${ }^{1}$ Kelainan bawaan dapat memengaruhi bentuk organ, fungsi organ ataupun keduanya. Tingkatannya bervariasi dari ringan hingga berat. Kemampuan bayi untuk bertahan hidup bergantung pada bagian tubuh yang mengalami kelainan. ${ }^{2}$

Kelainan kongenital merupakan masalah kesehatan yang penting karena merupakan salah satu penyebab utama kematian bayi di dunia. ${ }^{3}$ Kelainan kongenital menjadi beban kesehatan bagi negara dengan penghasilan rendah hingga menengah, bahkan beberapa negara tidak memiliki fasilitas yang memadai untuk menangani kejadian ini sehingga dapat menimbulkan efek jangka panjang. ${ }^{4}$ Dari keseluruhan bayi dengan kelainan bawaan lebih dari $70 \%$ meninggal pada bulan pertama. ${ }^{5}$

Menurut WHO, setiap tahunnya setidaknya 8 juta bayi di seluruh dunia mengalami kejadian kelainan kongenital. Di Amerika serikat, setiap tahunnya terdapat 120.000 bayi dengan kelainan kongenital. Sekitar 3\% bayi atau satu dari 33, dilahirkan dengan kelainan kongenital struktural. ${ }^{6}$ Prevalensi kelahiran kelainan kongenital di Inggris ialah $2 \%$ dan di Afrika Selatan $1,49 \%$. Di Lebanon, insiden kelainan kongenital dilaporkan sebesar $1,64 \%$ di Beirut Selatan. ${ }^{7}$

Di Indonesia, hasil Riset Kesehatan Dasar (RISKESDAS) menjelaskan bahwa kelainan kongenital merupakan salah satu penyebab kematian bayi. Pada bayi usia 0-6 hari, persentase kematian bayi yang disebabkan kelainan kongenital sebesar 1,4\%, sedangkan pada usia 7-28 hari, terdapat peningkatan sebesar 18,1\%. Menurut Global Report on Birth Defects oleh March of Dimes Birth Defects Foundation pada tahun 2006, prevalensi kejadian kelainan kongenital pada bayi di Indonesia ialah 59,3 per 1.000 kelahiran hidup. Angka ini menunjukkan bahwa Indonesia masih termasuk dalam negara dengan prevalensi cukup tinggi dari bayi berkelainan kongenital di antara negara Asia Tenggara lainnya. ${ }^{2}$

Di Sulawesi Utara, jumlah bayi yang mengalami kejadian kelainan kongenital yang lahir di RSUP Prof. Dr. R. D. Kandou Manado periode Januari 2015-Juli 2016 ialah 66 kasus. Kejadian kelainan kongenital terjadi lebih banyak pada jenis kelamin lakilaki yaitu 48 orang $(72,7 \%)$ dibandingkan jenis kelamin perempuan yaitu 48 orang $(27,3 \%)$, dengan kejadian kelainan kongenital terbanyak ialah penyakit jantung bawaan (PJB) yaitu 27 kasus. $^{8}$ Angka kematian bayi (AKB) di Sulawesi Utara menurut SKDI 2013 masih di bawah angka nasional. Menurut data dari Dinas Kesehatan Provinsi Sulawesi Utara tahun 2017, dalam 266 kasus kematian balita periode 2016 kelainan kongenital masih menyumbang 33 kasus sebagai penyebab kematian balita, tertinggi di peringkat ke empat. ${ }^{9}$

Belum diketahui dengan pasti etiologi dari kelainan kongenital. Sebesar 40\%- 60\% kasus tidak diketahui penyebabnya, namun, diperkirakan mutasi gen merupakan faktor yang paling berpengaruh terhadap terjadinya kelainan kongenital. ${ }^{10} \mathrm{Di}$ antara beberapa etiologi terjadinya kelaianan genetik, kelainan kromosom mencapai $6 \%$, kelainan gen tunggal $25 \%$, dan multifaktorial 20$30 \%$. Pernikahan antar sesama keluarga dianggap sebagai salah satu faktor penting yang berkontribusi terhadap kejadian kelainan kongenital. ${ }^{7}$

Terdapat beberapa faktor risiko yang mendukung terjadinya kelainan kongenital seperti faktor genetik, lingkungan, infeksi, status gizi, sosial ekonomi, dan demografi. $^{2}$ Berbicara mengenai faktor risiko kejadian kelainan kongenital perlu juga diperhatikan faktor risiko pra-konsepsi, riwayat ayah dan ibu, sosial budaya, dan faktor risiko pasca konsepsi. ${ }^{10}$ Beberapa karakteristik ibu lainnya yang termasuk dalam faktor risiko kejadian kelainan kongenital yaitu riwayat penyakit, paritas, dan jarak antar kelahiran. ${ }^{11}$

\section{METODE PENELITIAN}

Penelitian ini merupakan suatu litera- 
ture review. Penelusuran literatur dilakukan pada beberapa database baik nasional maupun internasional seperti Google Scholar dan PubMed dengan kombinasi kata kunci sebagai berikut yaitu, faktor Risiko, kelainan bawaan, kelainan kongenital, neonatus.

\section{HASIL PENELITIAN}

Setelah melalui tahap seleksi didapatkan beberapa literatur yang memenuhi kriteria inklusi dan eksklusi. Penelitian Pavlovi et al $^{12}$ mendapatkan bahwa faktor risiko kelainan kongenital yang bermakna yaitu faktor kelainan genetik $(\mathrm{p}=0,001)$.

Penelitian oleh Căpățînă dan Cozaru ${ }^{10}$ melaporkan bahwa terdapat tiga faktor risiko dengan frekuensi tertinggi yaitu: paparan asap rokok (aktif atau pasif) $(57,42 \%)$, multiparitas $(56,16 \%)$, dan riwayat abortus (47\%).

Penelitian Al-Musawi et al $^{13}$ mendapatkan bahwa kelainan kongenital lebih sering terjadi pada laki-laki dibandingkan perempuan (60:40\%). Persentase kelainan kongenital oleh faktor usia ibu >34 tahun $(66,7 \%)$, IMT ibu $\geq 30(61,7 \%)$, hipertensi $(56,6 \%)$, anemia $(63,3 \%)$, pengobatan mandiri $(60 \%)$, riwayat keluarga dengan kelainan kongenital (80\%), penyakit menular selama kehamilan (60\%), aborsi sebelumnya $(58,3 \%)$, tidak konsumsi asam folat $(70 \%)$, dan status sosialekonomi rendah $(65 \%)$.

Mohammed et al ${ }^{14}$ menyatakan bahwa kelainan kongenital lebih sering tejadi pada laki-laki dibandingkan perempuan $(65,9 \%$ : $34,1 \%$ ). Faktor risiko yang menyebabkan kelainan kongenital yaitu, usia ibu 20-30 tahun $(58,8 \%)$, multigravida $(60,6)$, multiparitas $(88,7 \%)$, riwayat aborsi $(45,5 \%)$, dan konsumsi obat-obatan saat hamil (80\%).

Penelitian oleh Ajao dan Adeoye ${ }^{15}$ mendapatkan bahwa kelainan kongenital lebih sering terjadi pada laki-laki dibandingkan perempuan $(53,7 \%: 46,3 \%)$. Faktor risiko lainnya yang diteliti tidak terbukti berhubungan dengan kelainan kongenital. Namun hasil penelitiannya menunjukkan faktor komplikasi obstetri $(\mathrm{p}=0,518)$, berat badan lahir $(\mathrm{p}=0,420)$, dan usia maternal $(\mathrm{p}=0,393)$.

Penelitian Aloui et al ${ }^{16}$ mendapatkan bahwa kelainan kongenital tidak berhubungan secara bermakna dengan berat badan lahir rendah $(p=0,07)$. Namun, kelainan kongenital lebih bermakna pada usia kehamilan $>14$ minggu $(p=0,01)$, usia $i b u$, dan faktor rhesus, sedangkan asal ibu tidak secara bermakna terkait dengan kelainan kongenital $(\mathrm{p}>0,05)$.

Polii et $\mathrm{al}^{8}$ mendapatkan bahwa lakilaki lebih sering mengalami kelainan kongenital dibanding perempuan $(72,7 \%: 27,3 \%)$. Tidak terdapat faktor risiko lain yang diteliti dan terbukti berhubungan dengan kelainan kongenital. Namun berdasarkan distribusi tertinggi neonatus dengan kelainan kongenital menurut ibu yang terkena infeksi selama kehamilan, didapatkan 20 ibu (30,3\%) yang melahirkan bayi dengan kelainan kongenital baik infeksi TORCH maupun infeksi lain.

Penelitian oleh Hussein et al ${ }^{17}$ melaporkan bahwa laki-laki (47 kasus; 61,04\%, $\mathrm{RR}=1,03)$ lebih sering mengalami kelainan kongenital dibandingkan perempuan (30 kasus; 38,96\%, RR=0,95). Berdasarkan faktor multiparitas didapatkan kasus kelainan kongenital pada 60 kasus $(77,92 \%$; $R R=$ 1.24) kasus. Terdapat 45 ibu berusia 20-30 tahun $(58,44 \%, \mathrm{RR}=1,1)$ yang melahirkan bayi dengan kelainan kongenital. Dalam penelitian ini, 54 ibu dari bayi dengan kelainan kongenital $(70,13 \%, \mathrm{RR}=2)$ memiliki hubungan darah dengan suami. Selain itu, terdapat $6 \mathrm{ibu}$ dengan diabetes gestasional $(7,79 \%, \mathrm{RR}=1,95)$.

Penelitian Rizk et $\mathrm{al}^{5}$ mengemukakan bahwa kelainan kongenital lebih sering tejadi pada laki-laki dibanding perempuan $(58,3 \%$ : $41,7 \%$ ). Terdapat faktor risiko penyebab kelainan kongenital secara bermakna dikaitkan dengan berat badan bayi yang relatif rendah $(\mathrm{p}=0,027)$, serta konsumsi alkohol dan obatobatan oleh ibu saat hamil $(\mathrm{OR}=10,42$; $\mathrm{p}=0,007$ dan $\mathrm{OR}=5,23 ; \mathrm{p}<0,001)$ dikaitkan dengan risiko kelainan kongenital yang lebih tinggi.

Penelitian Hasanah ${ }^{18}$ melaporkan bahwa kelainan kongenital lebih sering terjadi pada laki-laki dibandingkan perempuan (69\%:31\%). Berdasarkan usia ibu, persentase kelainan kongenital lebih banyak pada 
bayi dengan usia ibu antara 20-34 tahun $(77,4 \%)$. Status sosioekonomi merupakan faktor risiko terbanyak dimana status sosioekonomi rendah pada sebanyak 43 bayi $(51,2 \%)$ yang mengalami kejadian kelainan kongenital.

\section{BAHASAN}

Berdasarkan laporan penelitian yang didapat, diketahui bahwa prevalensi dari penyakit kongenital memiliki rentang yang sangat besar. Penelitian yang dilakukan oleh Rizk et $\mathrm{al}^{5}$ mendapatkan prevalensi penyakit kongenital sebesar 2,4\%. Sementara itu penelitian yang dilakukan oleh Alaoui et $\mathrm{a}^{16}$ melaporkan prevalensi sebesar 46,47\%. Selain itu terdapat dua penelitian yang dilakukan di Indonesia yang tidak menyebutkan prevalensi dari kelainan kongenital yang ditemukannya.

Penelitian di Indonesia menunjukkan perbandingan tingkat kejadian kelainan kongenital yang terjadi pada laki-laki dan perempuan. Berdasarkan penelitian Polii et $\mathrm{al}^{8}$ didapatkan dominasi kejadian kelainan kongenital pada laki-laki sebesar 58,3\%, yang selaras dengan penelitian Hasanah ${ }^{18}$ yang melaporkan tingkat kejadian kelainan kongenital sebesar $69 \%$ pada laki-laki. Hal ini didukung oleh hasil penelitian lainnya yaitu oleh Al-Musawi et $\mathrm{al}^{13}$ (60\%), Mohammed et $\mathrm{al}^{14}(65,9 \%)$, Rizk et $\mathrm{al}^{5}$ $(58,3 \%)$, serta Ajao dan Adeoye ${ }^{15}(53,7 \%)$.

Beberapa laporan penelitian yang digunakan dalam kajian ini menyebutkan faktor risiko dan kelainan kongenital yang sangat banyak, sehingga peneliti hanya mencantumkan beberapa faktor risiko dan kelainan kongenital saja dari setiap laporan penelitian tersebut yang memiliki frekuensi atau pengaruh terbesar.

Faktor risiko yang paling banyak diidentifikasi berhubungan dengan kelainan kongenital ialah karakteristik ibu. Usia ibu 20 tahun atau lebih tua menjadi faktor risiko yang paling banyak' disebutkan. Pada penelitian oleh Pavlovic et al ${ }^{12}$ diperoleh tingkat kejadian yang lebih tinggi pada usia ibu lebih tua yang disebabkan oleh faktor genetik sedangkan penelitian oleh Mohammed et al ${ }^{14}$ mendapatkan nilai sebesar 58,8\% untuk kejadian kelainan kongenital pada ibu yang berusia 20-30 tahun. Selain itu, penelitian oleh Hasanah ${ }^{18}$ mendapatkan nilai sebesar 79,8\% untuk kejadian kelainan kongenital pada bayi dengan ibu yang berusia 20-34 tahun; penelitian oleh AlMusawi et al $^{13}$ mendapatkan nilai sebesar $66,7 \%$ untuk kejadian kelainan kongenital pada ibu yang berusia lebih dari 34 tahun; dan penelitian oleh Hussein ${ }^{17}$ mlaporkan persentase sebesar $58,44 \%(\mathrm{RR}=1,1)$ pada ibu berusia 20-30 tahun.

Karakteristik terkait riwayat obstetri juga disebutkan berhubungan dengan kelainan kongenital. Penelitian Capatina dan Cozaru $^{10}$ mengemukakan nilai sebesar $56,16 \%$, Mohammed et al ${ }^{14}$ sebesar $88,7 \%$, dan Hussein ${ }^{17}$ sebesar $77,92 \%$ yang mendukung multiparitas sebagai faktor risiko kelainan kongenital. Riwayat abortus juga terbukti menjadi faktor risiko terjadinya kelainan kongenital, sebagaimana yang disebutkan oleh penelitian Capatina dan Cozaru $^{10}$ yang mendapatkan persentase sebesar $47 \%$, Hussein ${ }^{17}$ sebesar 20,78\% $(\mathrm{RR}=1.22)$, dan Al-Musawi et $\mathrm{al}^{13}$ sebesar $58,3 \%$.

Penyakit yang diderita ibu selama hamil juga didapatkan berhubungan dengan kelainan kongenital. Penelitian oleh Hussein ${ }^{17}$ mendapatkan persentase sebesar 7,79\% $(\mathrm{RR}=1,95)$ untuk terjadinya kelainan kongenital pada bayi dengan ibu menyandang diabetes gestasional. Perilaku dan gaya hidup ibu selama hamil juga dapat menjadi faktor risiko terjadinya kelainan kongenital. Penelitian yang dilakukan oleh Capatina dan Cozaru $^{10}$ mendapatkan persentase sebesar $57,52 \%$ untuk hubungan paparan asap rokok, baik aktif maupun pasif dengan kelainan kongenital. Rizk et $\mathrm{al}^{5}$ melaporkan bahwa konsumsi alkohol juga menjadi faktor risiko terjadinya kelainan kongenital dengan nilai $\mathrm{OR}=10,42$ dan $\mathrm{p}=0,007$. Pada penelitian yang sama, konsumsi obat-obatan juga terbukti sebagai faktor risiko terjadinya kelainan kongenital dengan nilai $\mathrm{OR}=5,23$ dan $\mathrm{p}<0,001$. Hal ini didukung oleh penelitian Mohammed et $\mathrm{al}^{14}$ yang mendapatkan persentase kelainan kongenital sebesar $80 \%$. Sementara itu, penelitian Al-Musawi et $\mathrm{al}^{13}$ 
melaporkan persentase sebesar $70 \%$ untuk kejadian kelainan kongenital pada bayi dengan ibu yang tidak mengkonsumsi asam folat selama hamil.

Faktor riwayat keluarga dan lingkungan juga terbukti menjadi faktor risiko terjadinya kelainan kongenital. Penelitian AlMusawi et al $^{13}$ melaporkan bahwa riwayat keluarga dapat menjadi faktor risiko terjadinya kelainan kongenital sebesar $80 \%$. Selain itu hubungan darah antara suami dan istri juga menjadi faktor risiko terhadap terjadinya kelainan kongenital. Penelitian Hussein ${ }^{17}$ mendapatkan persentase sebesar $70,13 \%(\mathrm{RR}=2)$ pada ibu hamil yang memiliki hubunngan darah dengan suaminya. Selain itu, penelitian Hasanah ${ }^{18}$ menyebutkan bahwa faktor lingkungan berupa status sosioekonomi rendah $(51,2 \%)$ ternyata juga merupakan faktor risiko dari terjadinya kelainan kongenital. Hal ini dikuatkan oleh penelitian Al-Musawi et al ${ }^{13}$ mendapatkan persentase sebesar $65 \%$ untuk kelainan kongenital yang terjadi pada status sosioekonomi rendah.

\section{SIMPULAN}

Terdapat beberapa faktor risiko yang berhubungan dengan kejadian kelaianan kongenital pada bayi, yaitu: usia ibu, multiparitas, riwayat abortus, kelainan kongenital pada kehamilan sebelumnya, diabetes gestasional, paparan asap rokok, konsumsi alkohol, konsumsi obat-obatan, tidak mengonsumsi asam folat, riwayat keluarga mengalami kelainan kongenital, adanya hubungan darah antara ayah dan ibu, dan status sosioekonomi rendah.

Bagi penelitian selanjutnya agar menggunakan laporan penelitian yang mencantumkan karakteristik subjek penelitian agar dapat dianalisis secara menyeluruh.

Bagi tenaga medis dan masyarakat yang mendapatkan faktor risiko tersebut pada ibu hamil agar mewaspadai akan terjadinya kelainan kongenital

\section{Konflik Kepentingan}

Penulis menyatakan tidak terdapat konflik kepentingan dalam studi ini.

\section{DAFTAR PUSTAKA}

1. WHO. Congenital anomalies. Published 2016. https://www.who.int/news-room/factsheets/detail/congenital-anomalies

2. Kementerian Kesehatan RI. Pusat Data dan Informasi: Kelainan Bawaan. Published online 2018; p. 1-6.

3. Hoyert DL, Xu J. National vital statistics reports deaths: preliminary data for 2011 . Natl Vital Stat Rep. 2012;61(6):1-51. Available from: http://www.ncbi.nlm. nih.gov/pubmed/24984457

4. WHO. Congenital anomalies. Available from: https://www.who.int/health-topics/ congenital-anomalies\#tab=tab_1

5. Rizk F, Salameh P, Hamadé A, Francine R, Pascale S, Aline H. Congenital anomalies: prevalence and risk factors. J Public Health. 2014;2(2):58-63. Doi:10.13189/ ujph.2014.020204

6. CDC. Data \& Statistics on Birth Defect [Internet]. Available from: https://www. cdc.gov/ncbddd/birthdefects/data.html

7. Risk F, Pascale S, Hamadé A. Congenital anomalies: prevalence and risk Factors. Univers J Public Heal. 2014;2(2):58-63. Doi:10.13189/UJPH.2014.020204

8. Polii EG, Wilar R, Umboh A. Faktor risiko yang berhubungan dengan kejadian kelainan bawaan pada neonatus di RSUP Prof Dr. R. D. Kandou Manado. e-CliniC. 2016; 4(2). Doi:10.35790/ecl.4.2.2016.14466

9. Profil Kesehatan Provinsi Sulawesi Utara 2016. Dinas Kesehatan Daerah Provinsi Sulawesi Utara, 2017.

10. Căpăţină D, Cozaru GC. Risk factors associated with congenital anomalies in children. ARS Medica Tomitana. 2015; 21(2):105-111. Doi:10.1515/arsm-2015 $-0029$

11. Maryanti D, Kusumawati DD. Faktor-faktor Risiko terjadinya kelainan kongenital. J Kesehat Al-Irsyad. 2015;VII(1):36-45.

12. Pavlović I, Plećaš D, Plešinac S, Dotlić J, Stojanović N. Congenital anomalies: occurrence and potential risk factors. Vojnosanit Pregl. 2020;77(3):317-323. Doi:10.2298/VSP180320088P

13. Al-Musawi KM, Shawq AH, Majeed Z, Zaid $\mathrm{S}$, Ibraheem $\mathrm{H}$. Risk factors for congenital anomalies in neonatal intensive care unit in Baghdad city. Medico-Legal Updat. 2020;20(1):1168-1174. Doi:10. 37506/v20/il/2020/mlu/ 194460

14. Mohammed A, Amal H, Safwat A. Prevalence 
and risk factors of congenital anomalies among neonates in Assuit University Children Hospital. 4th International Scientific Nursing Conference. Sustainability in Excellence: The Future of Nursing. Egypt: Port-Said University, 2018.

15. Ajao AE, Adeoye IA. Prevalence, risk factors and outcome of congenital anomalies among neonatal admissions in Ogbomoso, Nigeria. BMC Pediatr. 2019; 19(1):1-10. Doi:10.1186/s12887-0191471-1

16. Aloui M, Nasri K, Ben Jemaa N, Ben Hamida AM, Masmoudi A, Gaigi S, et al.
Congenital anomalies in Tunisia: Frequency and risk factors. J Gynecol Obstet Hum Reprod. 2017;46(8):651655. Doi:10. 1016/j.jogoh.2017.05.006

17. Hussein A. A five years retrospective study of congenital anomalies at Karbala City, Iraq. Karbala Journal of Medicine. 2017;10(1):2620-7.

18. Hasanah R. Prevalensi dan faktor risiko terjadinya kelainan bawaan pada bayi baru lahir di Rumah Sakit Umum Pusat Haji Adam Malik, Medan, tahun 2012-2015. Repository USU. 2019. Available from: repositori.usu.ac.id 